\title{
Identification of the Cutaneous Basement Membrane Zone Antigen and Isolation of Antibody in Linear Immunoglobulin A Bullous Dermatosis
}

John J. Zone, Ted B. Taylor, Donald P. Kadunce, and Laurence J. Meyer

Division of Dermatology, Department of Internal Medicine, University of Utah School of Medicine, Salt Lake City, Utah 84132; and

Division of Dermatology, Department of Internal Medicine, Veterans Administration Medical Center, Salt Lake City, Utah 84148

\begin{abstract}
Linear IgA bullous dermatosis (LABD) is a rare blistering skin disease characterized by basement membrane zone deposition of IgA. This study identifies a tissue antigen detected by patient serum and then isolates the autoantibody using epidermis and protein bands blotted on nitrocellulose as immunoabsorbents.

Sera from 10 patients ( 9 with cutaneous disease and 1 with cicatrizing conjunctivitis) were evaluated. Indirect immunofluorescence revealed an IgA anti-basement membrane antibody in 6 of 10 sera with monkey esophagus substrate and 9 of 10 sera with human epidermal substrate. Immunoblotting was performed on epidermal and dermal extracts prepared from skin separated at the basement membrane zone with either sodium chloride or EDTA. Saline-separated skin expressed a 97-kD band in dermal extract alone that was recognized by 4 of 10 sera. EDTA-separated skin expressed the $97-\mathrm{kD}$ band in both epidermal ( 4 of 10 sera) and dermal ( 6 of 10 sera) extract. Immunoabsorption of positive sera with epidermis purified an IgA antibody that reacted uniquely with the 97-kD band. In addition, IgA antibody bound to nitrocellulose was eluted from the 97-kD band and found to uniquely bind basement membrane zone.
\end{abstract}

It is likely that the 97-kD protein identified by these techniques is responsible for basement membrane binding of IgA in LABD. (J. Clin. Invest. 1990. 85:812-820.) IgA • dermatitis herpetiformis - linear IgA bullous dermatosis - basement membrane zone

\section{Introduction}

Linear IgA bullous dermatosis (LABD) ${ }^{1}$ is a rare acquired subepidermal blistering disease of the skin which has been defined on the basis of its unique immunopathologic finding of linear IgA along the cutaneous basement membrane (1). LABD was initially considered to be a variant of dermatitis herpetiformis (2). However, LABD has been separated from

This work was presented at the Western regional meeting of the Society for Investigative Dermatology in Carmel, CA, February, 1988, and at the National meeting of the Society for Investigative Dermatology at Washington DC, May, 1988.

Address reprint requests to Dr. J. J. Zone, Division of Dermatology, 50 North Medical Drive, Salt Lake City, UT 84132.

Received for publication 22 August 1988 and in revised form 12 October 1989.

1. Abbreviations used in this paper: ATPBS, PBS with BSA and Tween 20; LABD, linear IgA bullous dermatosis; ZIA, zone immunoaffinity.

The Journal of Clinical Investigation, Inc.

Volume 85, March 1990, 812-820 classical dermatitis herpetiformis that demonstrates granular deposition of IgA in dermal papillary tips. Patients with dermatitis herpetiformis also have a high frequency of the HLA B8 DR3 haplotype, and gluten-sensitive enteropathy, which is not present in LABD patients $(3,4)$. Some patients with LABD demonstrate a circulating IgA-class anti-basement membrane antibody on indirect immunofluorescence, whereas sera from patients with dermatitis herpetiformis have not demonstrated a circulating antibody that binds to skin (2). Immunoelectron microscopy in LABD reveals two patterns of IgA deposition. One group has immunoglobulin deposition in the sublamina densa, whereas the second group shows deposition of immunoglobulin in the lamina lucida (5-8).

LABD can also be contrasted with other subepidermal blistering diseases of the skin on the basis of immunopathology. Both epidermolysis bullosa acquisita and bullous pemphigoid demonstrate the deposition of IgG-class antibody along the basement membrane on direct immunofluorescence and frequently a circulating IgG-class anti-basement membrane antibody. The epidermolysis bullosa acquisita antigen has been identified as a $290-\mathrm{kD}$ protein that is type VII collagen and is present in the sub-basal lamina $(9,10)$. The major bullous pemphigoid antigen has been identified as a $240-\mathrm{kD}$ epidermal protein present in the lamina lucida $(11,12)$. Because some patients with LABD have deposition of IgA in the lamina lucida, LABD has been referred to as "IgA pemphigoid" by some, implying that it is simply an IgA-class immune response to the bullous pemphigoid antigen (7).

We present evidence here that sera from patients with linear IgA disease contain an IgA-class antibody that selectively binds a $97-\mathrm{kD}$ protein extracted from both normal human epidermis and dermis. This antigen differs from the major bullous pemphigoid antigen and the epidermolysis bullosa acquisita antigen on the basis of molecular weight and tissue distribution. Moreover, we show that this antibody can be isolated using both the human basement membrane zone and nitrocellulose as an immunoabsorbent. Antibody isolated by these techniques reacts uniquely with basement membrane and the $97-\mathrm{kD}$ protein.

\section{Methods}

Patient sera. Sera from 10 patients with linear IgA disease (age range 28-51 yr) seen over a 10-yr period were evaluated. Nine patients had lesions limited to the skin with sparing of mucous membranes and demonstrated linear deposition of IgA along the basement membrane when perilesional, clinically normal-appearing skin was biopsied. Serum from one patient with cicatrizing conjunctivitis and no cutaneous lesions was also evaluated. This patient demonstrated only IgA basement membrane deposition on conjunctival biopsy. Patients with both IgG and IgA deposition along the basement membrane were excluded. The serum from a bullous pemphigoid patient with an antibasement membrane antibody titer 1:10,240 on monkey esophagus was used as a control for Western blots of epidermal extract. Serum 
from a patient with epidermolysis bullosa acquisita with an anti-basement membrane antibody titer of $1: 1,280$ on monkey esophagus served as a control for Western blots of dermal extracts. Sera from laboratory personnel were used as normal controls.

Indirect immunofluorescence. Indirect immunofluorescence was performed on monkey esophagus sections (Immunofluorescent Testing Service, Buffalo, NY), and saline-split normal human skin. Normal human skin was obtained from cadavers, keratomed to a thickness of $0.5 \mathrm{~mm}$, washed in PBS $\left(0.126 \mathrm{M} \mathrm{NaCl}, 0.008 \mathrm{M} \mathrm{Na}_{2} \mathrm{HPO}_{4}\right.$, and 0.002 $\mathrm{M} \mathrm{KH}_{2} \mathrm{PO}_{4} \mathrm{pH} 7.2$ ), frozen at $-70^{\circ} \mathrm{C}$, thawed, then incubated in $1 \mathrm{M}$ $\mathrm{NaCl}$ with $10 \mu \mathrm{M}$ PMSF for $18 \mathrm{~h}$ at $4^{\circ} \mathrm{C}$. The epidermis and dermis were then separated, washed in PBS, imbedded in OCT compound (Miles Scientific Div., Naperville, IL), and stored at $-70^{\circ} \mathrm{C}$. Within 1 mo, 6- $\mu \mathrm{m}$ sections were cut on a cryostat microtome. Test sera were then progressively diluted and applied to monkey esophagus and saline-split dermis and epidermis, incubated for $30 \mathrm{~min}$ at $25^{\circ} \mathrm{C}$, washed with PBS, and then stained with fluorescein-conjugated anti-IgG diluted 1:60 in PBS (Cappel Laboratories, Malvern, PA), gamma chainspecific, total protein $31.7 \mathrm{mg} / \mathrm{ml}$, antibody concentration $5.0 \mathrm{mg} / \mathrm{ml}$, fluorescein/protein ratio 4:1, or anti-IgA diluted 1:80 in PBS (Cappel Laboratories), alpha chain-specific, total protein $18.6 \mathrm{mg} / \mathrm{ml}$, antibody concentration $6.0 \mathrm{mg} / \mathrm{ml}$, and fluorescein/protein ratio $3: 0$, for 30 min, and finally washed with PBS. The limiting titer of anti-basement membrane antibody was then determined by epifluorescent microscopy.

Immunoelectron microscopy. Immunoelectron microscopy was performed on patients 2 and 3 (Table I) by Dr. Robert A. Briggaman at the University of North Carolina, Chapel Hill, NC. Both specimens revealed deposition of IgA within the lamina lucida.

Preparation of epidermal and dermal extracts. Normal human skin was separated from the dermis at the basement membrane zone by two methods: (a) $1 \mathrm{M}$ sodium chloride as described above; $(b)$ alternatively, $20 \mathrm{mM}$ EDTA, $10 \mu \mathrm{M}$ PMSF in PBS was substituted for $1 \mathrm{M}$ sodium chloride in the identical procedure noted above. Epidermal proteins were immediately extracted with $1 \%$ SDS and 5\% beta-mercaptoethanol in $25 \mathrm{mM}$ Tris buffer (pH 7.8) with $10 \mu \mathrm{M}$ PMSF by the method of Labib (13). Dermal proteins were extracted with $8 \mathrm{M}$ urea and $0.3 \mathrm{M}$ beta-mercaptoethanol in $25 \mathrm{mM}$ Tris buffer (pH 7.8) with $10 \mu \mathrm{M}$ PMSF for $1 \mathrm{~h}$ as described by Scaletta (14). The extract was then dialyzed extensively against distilled water at $4^{\circ} \mathrm{C}$ and then lyophilized.
SDS-PAGE was performed as outlined by Laemmli (15) in $6.5 \%$ (epidermal extract) and $8 \%$ (dermal extract) polyacrylamide. Proteins from nonstained gels were transferred electrophoretically onto nitrocellulose sheets (Western blots) as described by Towbin (16). LABD sera and normal human sera were diluted 1:10, epidermolysis bullosa acquisita serum was diluted $1: 200$, and bullous pemphigoid serum 1:100 in PBS with $0.5 \%$ BSA and $0.05 \%$ Tween 20 (ATPBS). Diluted sera were incubated with sectioned nitrocellulose sheets and developed using biotin-labeled second antibody and an avidin-biotin-peroxidase complex as described previously (17). Reaction times for all lanes of individual blots are identical.

Several specific antibodies were used for studies to characterize the location of separation of EDTA and saline-split skin. Mouse monoclonal antibody to laminin (Calbiochem-Behring Corp., San Diego, CA) was used at a dilution of 1:50 and the second antibody was fluorescein-conjugated goat antimouse IgG (IgG fraction, $13.5 \mathrm{mg} / \mathrm{ml}$ protein, $4.72 \mathrm{mg} / \mathrm{g}$ fluorescein to protein ratio; Cappel Laboratories) diluted 1:80 in PBS. Mouse monoclonal antibody to type IV collagen (Chemicon International Corp., Inc., El Segundo, CA) was used at a dilution of 1:200 in PBS and the second antibody was fluorescein-conjugated goat antimouse IgG diluted in PBS. Epidermolysis bullosa acquisita serum was diluted 1:200 in PBS. This serum has been characterized to demonstrate the classical reaction with the 290-kD type VII collagen (10). The second antibody was goat antihuman IgG as above. Mouse monoclonal antibody to fibronectin (Calbiochem-Behring Corp.) was diluted 1:80 and used with fluoresceinated goat anti-mouse antibody as above. All primary and secondary incubations were at room temperature for $30 \mathrm{~min}$. There were no significant differences in location of antibody binding detected between $1 \mathrm{M} \mathrm{NaCl}$ and the EDTA methods using antisera to type IV collagen, fibronectin, elastin, laminin, and type VII collagen (epidermolysis bullosa acquisita serum).

Basement membrane zone immunoaffinity (Fig. 1). $25 \mathrm{~cm}^{2}$ of epidermis separated by $1 \mathrm{M} \mathrm{NaCl}$ as noted above was diced into $\sim 35$ sections. This specimen was then incubated with $1 \mathrm{~cm}^{3}$ of the test serum diluted 1:5 in PBS with $10 \mu \mathrm{M}$ PMSF for $90 \mathrm{~min}$. The specimen was centrifuged at $3,000 \mathrm{~g}$ for $10 \mathrm{~min}$, and the supernatant discarded. The pellet was washed for 10 min three times in PBS, and then incubated in $5 \mathrm{~cm}^{3}$ of $20 \mathrm{mM}$ sodium citrate (pH 3.2) for $6 \mathrm{~h}$ at $37^{\circ} \mathrm{C}$. After centrifugation at $3,000 \mathrm{~g}$ for $10 \mathrm{~min}$, the supernatant was decanted and

Table I. Summary of Indirect Immunofluorescence and Western Blot Analyses of LABD Patient Sera

\begin{tabular}{|c|c|c|c|c|c|c|c|c|c|}
\hline \multirow[b]{3}{*}{$\begin{array}{l}\text { Patient } \\
\text { number }\end{array}$} & \multicolumn{2}{|c|}{ Serum } & \multicolumn{2}{|c|}{ Serum } & \multicolumn{2}{|c|}{ ZIA } & \multicolumn{3}{|c|}{ Nitrocellulose } \\
\hline & \multicolumn{2}{|c|}{ IgA antibody titer* } & \multicolumn{2}{|c|}{ Antibody (1:10) } & \multicolumn{2}{|c|}{ Eluted antibody } & \multicolumn{3}{|c|}{ Eluted antibody } \\
\hline & $\begin{array}{c}\text { Monkey } \\
\text { esophagus }\end{array}$ & $\begin{array}{c}\text { Split } \\
\text { human } \\
\text { skin }^{\ddagger}\end{array}$ & $\begin{array}{l}\text { Dermal } \\
\text { extract }\end{array}$ & $\begin{array}{c}\text { Epidermal } \\
\text { extract }\end{array}$ & $\begin{array}{l}\text { Dermal } \\
\text { extract }\end{array}$ & $\begin{array}{c}\text { Epidermal } \\
\text { extract }\end{array}$ & $\begin{array}{c}\text { Split } \\
\text { human } \\
\text { skin }\end{array}$ & $\begin{array}{l}\text { Dermal } \\
\text { extract }^{\S}\end{array}$ & $\begin{array}{c}\text { Epidermal } \\
\text { extract }^{\xi}\end{array}$ \\
\hline 1 & $1: 80$ & $1: 160$ & + & + & + & + & + & + & + \\
\hline 2 & $1: 80$ & $1: 160$ & + & + & + & + & + & + & + \\
\hline 3 & $1: 40$ & $1: 80$ & + & + & + & + & + & + & + \\
\hline 4 & $1: 160$ & $1: 160$ & + & + & + & ND & ND & ND & ND \\
\hline 5 & $1: 20$ & $1: 40$ & + & - & ND & ND & ND & ND & ND \\
\hline 6 & $1: 10$ & $1: 20$ & + & - & ND & ND & ND & ND & ND \\
\hline 7 & $<1: 10$ & $1: 20$ & - & - & ND & ND & ND & ND & ND \\
\hline 8 & $<1: 8$ & $1: 20$ & - & - & ND & ND & ND & ND & ND \\
\hline 9 & $<1: 10$ & $1: 10$ & - & - & ND & ND & ND & ND & ND \\
\hline 10 & $<1: 10$ & $<1: 10$ & - & - & ND & ND & ND & ND & ND \\
\hline
\end{tabular}

* Evaluation of serum IgA-class anti-basement membrane antibody titer by indirect immunofluorescence using monkey esophagus or $1 \mathrm{M}$ $\mathrm{NaCl}$-split human skin as a substrate. ${ }^{\ddagger}$ Staining of epidermal side of $1 \mathrm{M} \mathrm{NaCl}$-split human skin by indirect immunofluorescence. ${ }^{\S} \mathrm{Western}$ blot using patient serum diluted 1:10, ZIA antibody, or nitrocellulose-eluted antibody to probe dermal and epidermal extract for reactivity with the $97-\mathrm{kD}$ band. 


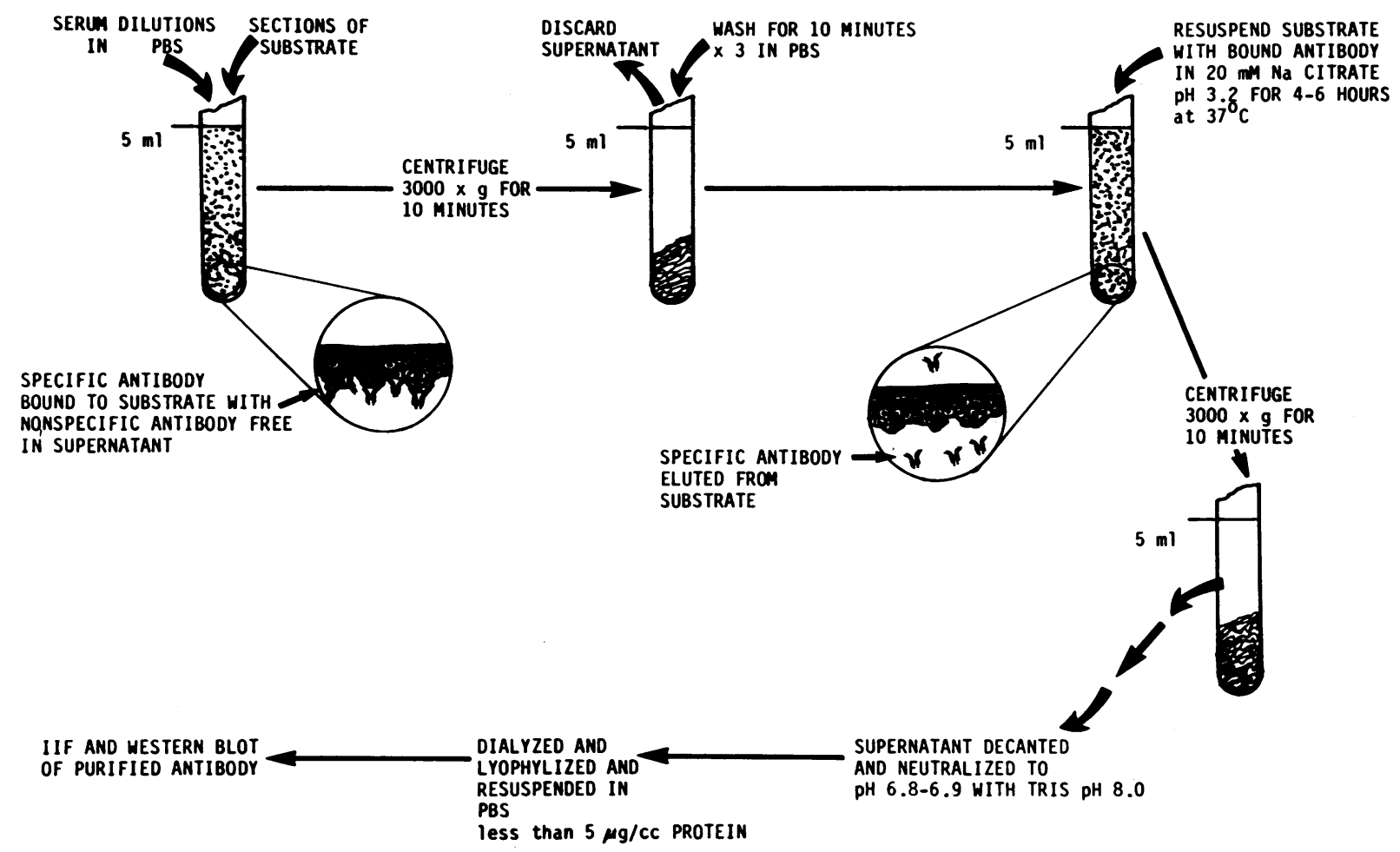

Figure 1. Basement membrane zone immunoaffinity. Anti-basement membrane antibody is first absorbed from serum with isolated human epidermis. The antibody is then eluted with citrate buffer, neutralized, dialyzed, lyophilized, and resuspended in PBS. Controls on the effectiveness of antibody absorption and elution are monitored with fluorescent microscopy.

neutralized to $\mathrm{pH} 7.3-7.5$ with $2 \mathrm{M}$ Tris ( $\mathrm{pH} 8.0$ ) and BSA was added to a final concentration of $0.2 \mathrm{~g} / 100 \mathrm{~cm}^{3}$. The supernatant was dialyzed overnight at $4^{\circ} \mathrm{C}$ against distilled water. The sample was then lyophilized and resuspended in $1 \mathrm{ml}$ of PBS (final BSA concentration $\sim 1 \mathrm{~g} / 100 \mathrm{~cm}^{3}$ ). Tween was then added to samples to be used for Western blot to a final concentration of $0.05 \%$.

Zone immunoaffinity (ZIA), performed as outlined above, was evaluated by immunofluorescence at various stages. Fig. $2 A$ reveals the indirect immunofluorescence of epidermis after the incubation with LABD serum diluted 1:5. It shows deposition of IgA along the basement membrane. Fig. $2 B$ is the indirect immunofluorescence of human epidermis after incubation with normal serum diluted 1:5 showing no antibody deposition. Fig. $2 C$ reveals the epidermis previously incubated with LABD serum after washing with sodium citrate, showing that antibody has been eluted from the epidermal sheet. Fig. $2 \mathrm{D}$ represents indirect immunofluorescence of the supernatant obtained after elution of the antibody on normal human epidermal substrate. This reveals an anti-basement membrane antibody present at a titer of 1:20 in the eluate. The final protein concentration (excluding that attributed to the added BSA) of this eluate was $<5 \mu \mathrm{g} / \mathrm{ml}$, indicating that the IgA-class anti-basement membrane antibody had been significantly purified from its initial relative concentration in serum.

Indirect immunofluorescence and Western blot of nitrocellulose immunoaffinity-purified serum. Protein bands on nitrocellulose blots of Laemmli gels were also used as immunoaffinity substrates to purify antibodies directed against specific proteins in dermal extract as described by Olmsted (18) and modified by Smith and Fisher (19). Vertical lanes from both sides of the nitrocellulose imprint of the gel were cut and immunochemically stained with sera to identify the bands of interest. Horizontal strips of nitrocellulose containing the antigen of interest, but not exposed to sera, were then cut and sera applied as 1:5 dilution in ATPBS for $2 \mathrm{~h}$. After washing in ATPBS, the antibodies were eluted in $600 \mu 120 \mathrm{mM}$ sodium citrate (pH 3.2), $0.05 \%$ Tween-20 for $3 \mathrm{~min}$ at $37^{\circ} \mathrm{C}$, and were immediately neutralized with $2.0 \mathrm{M}$ Tris $\mathrm{HCl}(\mathrm{pH} \mathrm{7.5)}$ to a final $\mathrm{pH}$ of 6.8 .

\section{Results}

Indirect immunofluorescence. Indirect immunofluorescence with LABD sera was performed with both monkey esophagus and saline-split normal human skin as substrates and developed with both fluorescein-conjugated anti-IgA and anti-IgG. No patient was found to have IgG-class anti-basement membrane zone antibody titers on either tissue source. Screening was done at a 1:10 dilution of serum. The IgA-class anti-basement membrane antibodies are reviewed in Table I. 6 of 10 patients were found to have positive titers of at least 1:10 IgA-class antibody when monkey esophagus was used as a tissue source. When saline-split skin was used as a tissue source, 9 of 10 patients had antibody titers of at least 1:10. This points out the superiority of saline-split skin as a tissue source for indirect immunofluorescence as has been previously reported in LABD (20). It should also be noted that all patients showed at least a one-tube dilution greater titer when salinesplit skin was used as a tissue source. 14 normal human sera were also tested in this manner and all were negative on indirect immunofluorescence for both antibody classes. Patient 4 is the patient with cicatrizing conjunctivitis without skin lesions.

Specific fluorescence was noted only at the basement membrane on the epidermal side of the split skin. No specific dermal fluorescence was noted.

Western blots of epidermal extract. Western blots of epidermal extracts were performed using skin separated by both 

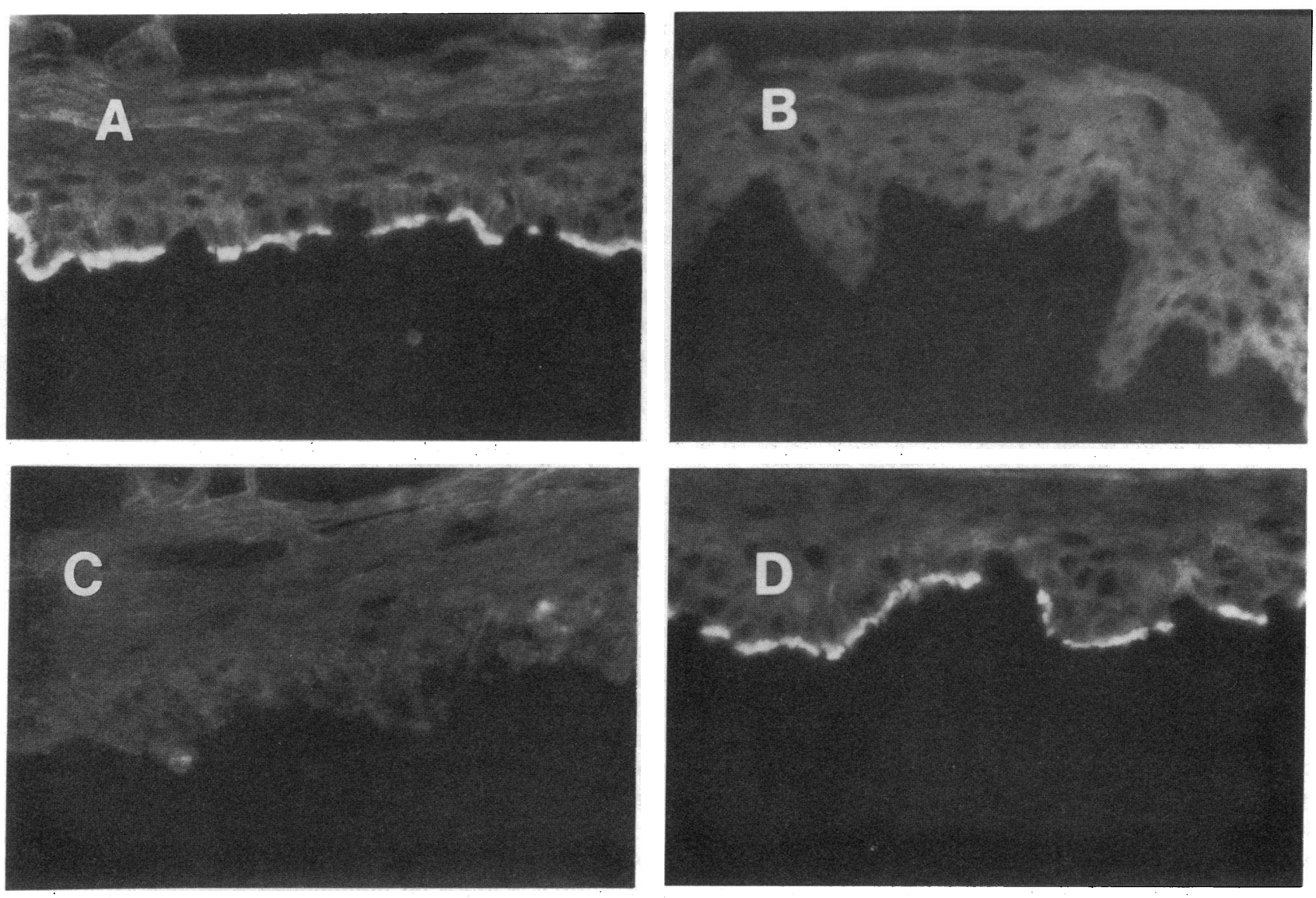

Figure 2. Fluorescent microscopy control of basement membrane zone immunoaffinity procedure. $(A)$ Staining of epidermal substrate with fluorescein-conjugated anti-IgA after initial incubation of LABD serum with sliced epidermal substrate demonstrating basement membrane deposition of IgA. (B) Staining of epidermal substrate for IgA after incubation with normal serum fails to demonstrate basement membrane deposition of IgA. (C) Staining of epidermal substrate for IgA after elution of antibody with citrate buffer reveals no basement membrane IgA. (D) Indirect immunofluorescence for IgA after incubating the citrate buffer eluted antibody with normal human epidermis demonstrates that the eluate contains IgA-class anti-basement membrane antibody.

the $1 \mathrm{M} \mathrm{NaCl}$ technique and the $20 \mathrm{mM}$ EDTA technique outlined in Methods. Identical concentrations (110 $\mu \mathrm{g} / \mathrm{lane})$ of epidermal extract obtained by both techniques were used for Western blots, exposed to sera, and developed with avidinbiotin-peroxidase complex. The Western blot of epidermal extract obtained from $1 \mathrm{M}$ saline-split skin showed no consistent antigen recognized by LABD sera, and the $97-\mathrm{kD}$ band subsequently discussed was not noted on these blots (data not shown). The Western blots of epidermal extract obtained from $20 \mathrm{mM}$ EDTA split skin exposed to LABD sera are shown in Fig. 3. Lane 1 is the no-primary antibody control. Lanes 2-4 are patients with LABD (patients 1-3, Table I). Results on patient 4 were similar (not shown). Lanes 5-7 were exposed to the normal human sera. All lanes were stained with anti-IgA. Several bands are recognized by sera from these patients with LABD; a consistent band at $97 \mathrm{kD}$, as well as a variety of other less consistent bands. The remainder of the LABD sera failed to demonstrate the $97-\mathrm{kD}$ band, but did show a number of less consistent bands (not shown). Relatively high protein concentration and low serum dilutions (1:10) were used to maximize sensitivity. As a result, increased background is noted with multiple bands in both test sera and normal sera. The positive control lane was exposed to bullous pemphigoid serum and developed with anti-IgG; it demonstrated a $240-\mathrm{kD}$ band (not shown).

Western blot of dermal extract. Fig. 4 demonstrates the Western blots of dermal extract prepared from EDTA-split skin exposed to sera and developed with avidin-biotin-peroxidase complex. Lanes 1-6 are LABD sera (patients 1-6, Table I) stained with anti-IgA. Lane 4 is serum from the patient with cicatrizing conjunctivitis. Lanes 7-9 are normal sera. A band in the $97-\mathrm{kD}$ range is noted with LABD and cicatrizing conjunctivitis patient sera. This becomes minimally detectable when sera with lower antibody titers are used (lanes 5 and 6 ). An additional dense $38-\mathrm{kD}$ band is noted with the cicatrizing conjunctivitis patient serum. The positive control lane was exposed to epidermolysis bullosa acquisita serum developed with anti-IgG and showed a characteristic $290-\mathrm{kD}$ band as well as some nonspecific staining (not shown). The protein concentration per lane in this blot is $112 \mu \mathrm{g} / \mathrm{lane}$. It should be noted that several additional bands can also be seen with normal human sera and large amounts of background with some test sera. This is a result of using high concentrations of dermal extract and low dilutions of test sera to maximize sensitivity for detection of antigen antibody, thus allowing detection of low titer or low avidity antibodies. The remainder of the sera 


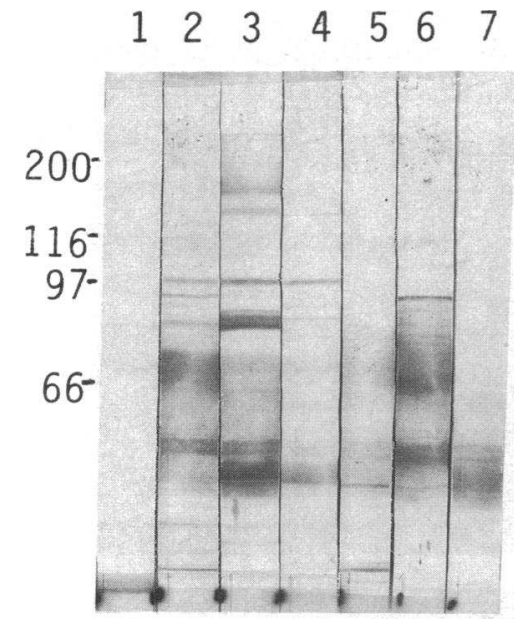

Figure 3. Western blot of epidermal extract from EDTA-separated skin. Nitrocellulose strips are incubated with patient serum at 1:10 dilution and developed with avidin-biotin-peroxidase complex and anti-IgA. Lane 1 is a control with no patient serum added. Lanes 2-4 are incubated with LABD patient sera. Lanes 5-7 are normal human sera. Multiple bands are identified by all sera. A consistent band at 97

$\mathrm{kD}$ is identified by the LABD sera. Lower titer LABD sera failed to identify the $97-\mathrm{kD}$ band.

(patients 7-10 in Table I) failed to produce a band with dermal extract (data not shown). Since these negative sera were the ones with the lowest titer of antibody, it was felt that lack of sensitivity was the likely reason for negative Western blots on these specimens. Control sera from 10 patients with bullous pemphigoid, 5 patients with pemphigus vulgaris, and 2 patients with epidermolysis bullosa acquisita were also evaluated for antibodies of IgA class against the 97- and 112-kD band. No reactivity of these sera was noted. We have previously reported similar Western blot analysis of 63 patients with der-

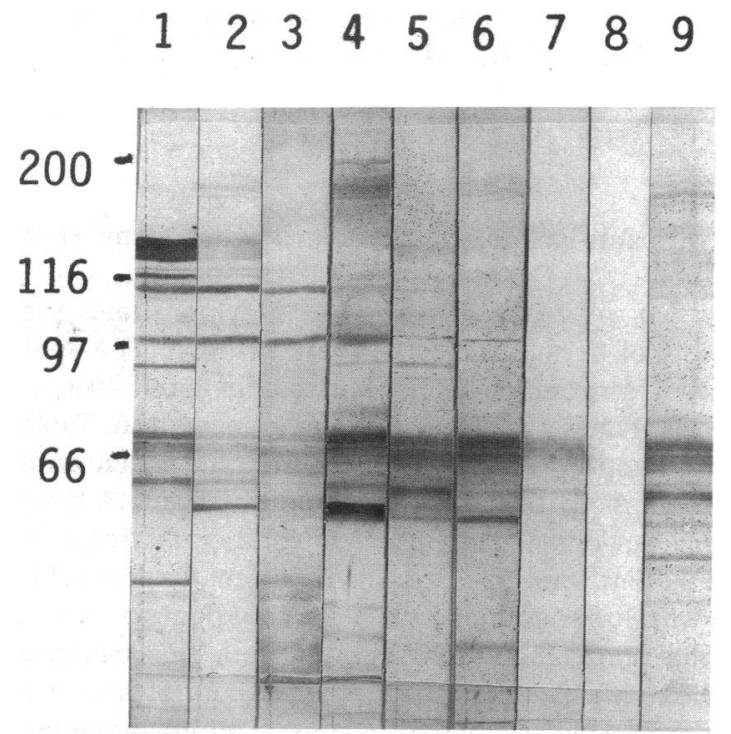

Figure 4. Western blot of dermal extract from EDTA-separated skin. Nitrocellulose strips are stained with patient serum at 1:10 dilution and developed with avidin-biotin-peroxidase complex and anti-IgA. Lanes 1-6 are incubated with LABD patient sera. Lane 4 is the cicatrizing conjunctivitis patient serum, and lanes 7-9 are normal human sera. A band is noted from LABD sera in the $97-\mathrm{kD}$ region, although all sera identify several other bands, some of which are more dense. The cicatrizing conjunctivitis serum detects an additional band at $38 \mathrm{kD}$. Significant background is noted due to low serum dilutions. matitis herpetiformis and 67 normal controls and neither the 97- or 112-kD band was consistently noted (21).

Western blot of EDTA-split skin epidermal extract stained with ZIA-purified serum (Fig. 5). Lane 1 is the no-primary antibody control. Lanes 2 and 3 are patients 1 and 2, Table I. Lanes 4 and 5 are normal human sera. Lanes $2 a-5 a$ are the ZIA-purified specimens of respective sera stained for IgA. Lanes $2 a$ and $3 a$ show preservation of the $97-\mathrm{kD}$ band after affinity purification using human epidermis. The remaining bands noted are related to nonspecific staining with the secondary antibody (compare with no-primary antibody in lane 1 ).

Western blot of dermal extract stained with ZIA-purified serum (Fig. 6). The Western blot of the dermal extract stained with ZIA-purified patient sera is shown in Fig. 6. Lanes 1-4 are stained with the LABD sera, lane 4 is the serum from the cicatrizing conjunctivitis patient, and lanes $1 a-4 a$ represent the corresponding ZIA-purified sera all stained for IgA. Lanes 5-6 are normal human sera, and lane $5 a-6 a$ are ZIA purification of normal human sera, stained for IgA. All patients demonstrated persistence of the $97-\mathrm{kD}$ band after the ZIA procedure. The cicatrizing conjunctivitis patient demonstrated purification of both a 38- as.well as a 97-kD band (lane $4 a$ ). The ZIA-purified specimens eliminate the considerable background produced by using test sera at low titers and high tissue extract concentrations. Dense bands that would seem to be of great importance are eliminated after purification (lane $1 a$ ).

Indirect immunofluorescence and Western blot of nitrocellulose immunoaffinity-purified serum. To further confirm that the antigen detected on immunoblot corresponded with the antigen detected using immunofluorescence, we used nitrocellulose blots of dermal extract as an affinity substrate for antibody purification and probed epidermis with the resulting antibody. Antibody was eluted from the 145-, 97-, and 55-kD bands of dermal extract as described in Methods and reacted with the basement membrane zone of EDTA-split epidermis with indirect immunofluorescence (Fig. 7). This demonstrates that the antibody reactive with the $97-\mathrm{kD}$, but not the 145 - and $55-\mathrm{kD}$ proteins, reacts with basement membrane zone.

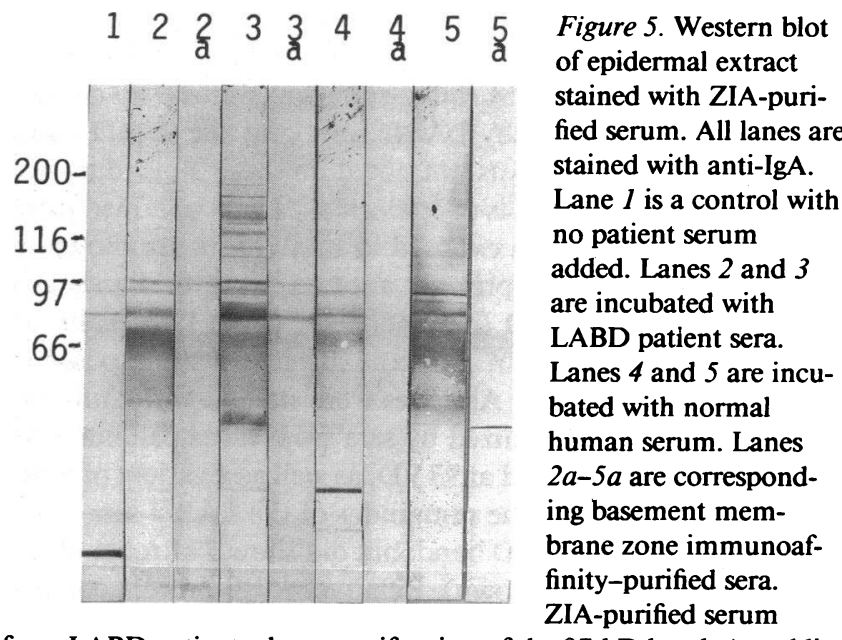

from LABD patients shows purification of the $97-\mathrm{kD}$ band. An additional band is seen at $80 \mathrm{kD}$ which represents nonspecific binding of the secondary antibody. The band at $30 \mathrm{kD}$ absorbed from normal serum $(5 a)$ is of uncertain significance. 


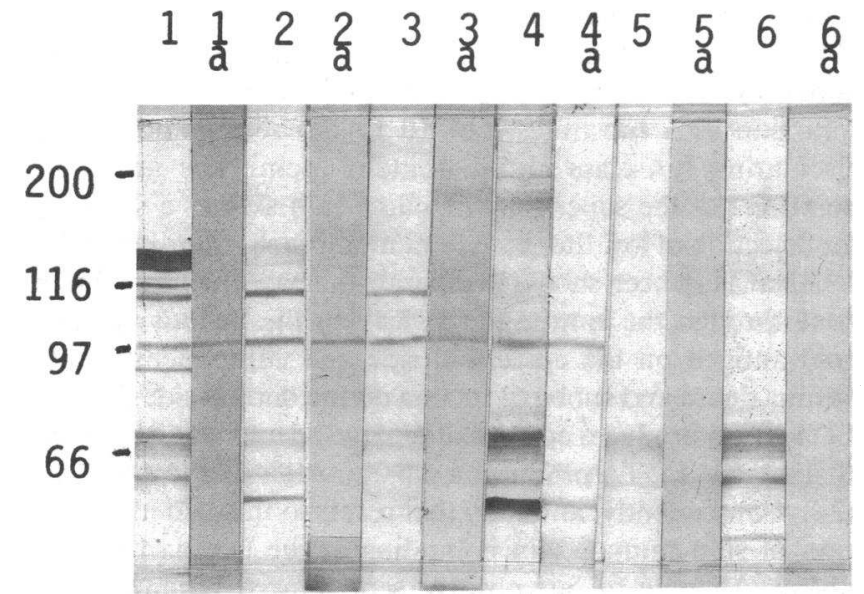

Figure 6. Western blot of dermal extract stained with ZIA-purified serum. Lanes 1-4 are incubated with LABD sera. Lane 4 is the cicatrizing conjunctivitis serum, and lanes 5 and 6 are normal human sera. Lanes $1 a-6 a$ are corresponding ZIA-purified sera. Specific staining of the $97-\mathrm{kD}$ band in dermal extract is noted in lanes $2 a, 3 a$, and $4 a$. Additional binding to a $38-\mathrm{kD}$ band is noted in the ZIA-purified cicatrizing conjunctivitis serum.

To identify possible cross-reactivity of antibodies eluted from nitrocellulose with other antigens detected on dermal extract, we used antibody eluted from specific bands of nitrocellulose to stain Western blots of dermal extracts. Fig. 8 is the Western blot of dermal extract stained with whole LABD serum from patient 1 (lane 1 ), antibody eluted from the 145-, 97-, and 55-kD bands (lanes 2, 3, and 4, respectively), and the negative control with no primary antibody (lane 5). This demonstrates that antibody eluted from the 145-kD band reacts with this antigen, as well as a lesser antigen at $120 \mathrm{kD}$ (lane 2). Antibody eluted from the $97-\mathrm{kD}$ band reacts with the $97-\mathrm{kD}$ band, as well as an antigen at $112 \mathrm{kD}$. This presumably represents a shared epitope between the 97- and 112-kD bands. Lastly, antibody eluted from the $55-\mathrm{kD}$ band reacts weakly with that antigen, but apparently shares no epitopes with other antigens. Nonspecific reactivity of the secondary antibody with proteins in the $50-70-\mathrm{kD}$ range is present in all lanes. This reapplication of eluted antibody further confirms that the antibodies under study were effectively eluted from nitrocellulose under conditions that retained their immunoreactivity. Similar results were noted with sera from patients 2 and 3 (Table I).

To establish that the $97-\mathrm{kD}$ band reactive in epidermal extract was the same antigen as that found in dermal extract, we used antibody eluted from the $97-\mathrm{kD}$ band on nitrocellulose blots of dermal extract. This revealed specific staining of only the 97-kD band on blots of epidermal extract and was done with sera from both patients 1 and 2 (not shown).

We conclude from the nitrocellulose elution studies that the antibody reactive with the $97-\mathrm{kD}$ band on dermal and epidermal extract is the antibody in serum that is responsible for the basement membrane zone staining seen on indirect immunofluorescence of serum.

\section{Discussion}

LABD is an uncommon blistering disease of the skin in which a vesicle forms in the basement membrane zone in association
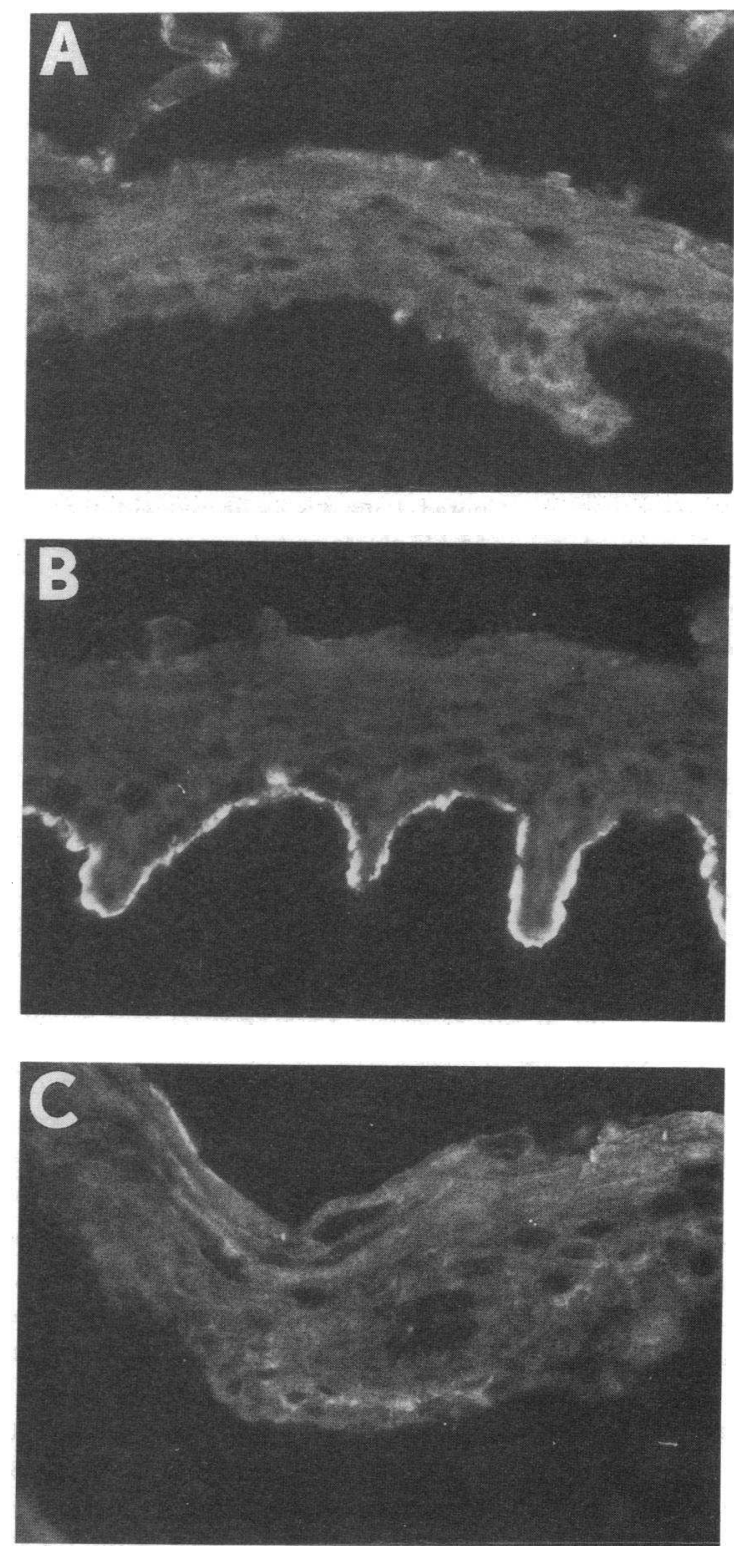

Figure 7. Indirect immunofluorescence of antibody eluted from nitrocellulose blots of dermal extract. Staining of epidermal substrate with fluorescein-conjugated anti-IgA after incubation with antibody eluted from various areas on nitrocellulose. $(A)$ Antibody eluted from the 145-kD area does not bind basement membrane. $(B)$ Antibody eluted from the $97-\mathrm{kD}$ area binds basement membrane. $(C)$ Antibody eluted from the 55-kD area does not bind basement membrane.

with the linear deposition of $\operatorname{IgA}$ in perilesional skin $(1,4,7)$. Inasmuch as IgA and complement are found along the basement membrane and because some patients have circulating IgA-class antibodies to basement membrane in their serum, it is likely that immunologic mechanisms are operative in the pathogenesis of individual blisters. Some authors have characterized LABD as a subclass of dermatitis herpetiformis, but numerous dissimilarities do not support this concept. Classical dermatitis herpetiformis is characterized by involvement of extensor surfaces with scattered papulovesicles, a $>85 \%$ incidence of the HLA B8 DR3 haplotype, the presence of gluten- 


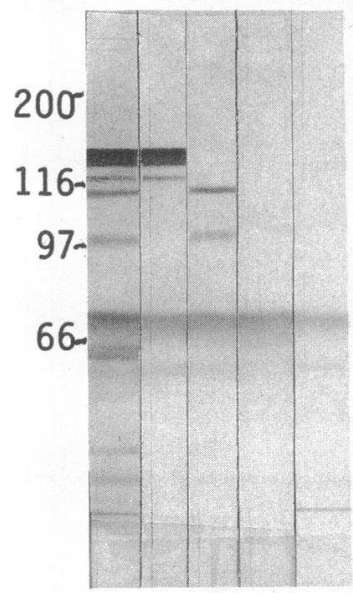

Figure 8. Western blot of antibody eluted from nitrocellulose blots of dermal extract. Nitrocellulose strips are developed with avidin-biotin-peroxidase complex and anti-IgA. Lane 1 is incubated with LABD serum diluted 1:10. Lane 2 is incubated with antibody eluted from the $145-\mathrm{kD}$ area and demonstrates preservation of immunoreactivity of that antibody with some apparent cross-reactivity with the $112-\mathrm{kD}$ band. Lane 3 is incubated with $97-\mathrm{kD}$ eluate and reactivity with both the $97-$ and $112-\mathrm{kD}$ bands is noted. Lane 4 is incubated with the 55-kD eluate and shows minimal reactivity. Lane 5 is the control that omits the primary antibody and shows nonspecific staining. sensitive enteropathy in $>90 \%$ of patients, and granular deposition of IgA in the basement membrane zone frequently focused in dermal papillary tips when perilesional, clinically normal-appearing skin is biopsied. LABD patients in contrast have a vesiculobullous disease with variable cutaneous distribution, a $30-40 \%$ incidence of the HLA B8 DR3 haplotype, a rare association with gluten-sensitive enteropathy, and linear deposition of $\operatorname{IgA}$ along the basement membrane $(1,3,4)$. Immunoelectron microscopy of LABD reveals deposition of IgA antibody in the lamina lucida of the basement membrane zone in some patients, and subbasal lamina deposition in others $(5,6,8)$. This contrasts sharply with the immunological findings in granular IgA disease where the IgA is bound to fibrillar components of elastic fibers in the papillary dermis $(5$, 6). Therefore, despite the likelihood that both dermatitis herpetiformis and LABD are mediated by an IgA-class immune response, their putative antigens are likely different.

Similar assumptions have been made for other blistering diseases, including bullous pemphigoid and epidermolysis bullosa acquisita, which are characterized by IgG antibody deposition along the basement membrane. Sera from most patients with bullous pemphigoid contain an antibody to a $240-\mathrm{kD}$ protein within the lamina lucida $(11,12)$, and sera from epidermolysis bullosa acquisita patients contain an antibody to type VII collagen present in the subbasal lamina (9, $10)$. Since both bullous pemphigoid and LABD may demonstrate deposition of immunoglobulin in the lamina lucida, it seemed possible that LABD simply represented an IgA-class response to the bullous pemphigoid antigen. Understanding of this relationship has been impeded by the presence of relatively low titer autoantibodies in LABD. We have evaluated multiple LABD sera for IgA-antibody reactivity with the basement membrane zone on indirect immunofluorescence and Western blot of epidermal and dermal extracts. We further purified the LABD autoantibody using the new technique of basement membrane zone immunoaffinity, as well as elution from nitrocellulose of IgA-class antibody that binds cutaneous basement membrane. These studies show that the LABD antigen is distinct from the described major bullous pemphigoid antigen.

6 of 10 serum samples from patients with LABD contained IgA-class autoantibodies that bound to the basement mem- brane of monkey esophagus, a common substrate for detection of basement membrane autoantibodies. When indirect immunofluorescence was performed on our sera using $1 \mathrm{M}$ salinesplit skin as a substrate, 9 of 10 LABD sera demonstrated circulating IgA-class anti-basement membrane antibody, pointing out the superiority of saline-split skin as a substrate for detection of low titer basement membrane zone antibodies. $1 \mathrm{M} \mathrm{NaCl}$ has been shown to separate the basement membrane zone through the lamina lucida leaving the bullous pemphigoid antigen on the epidermal side and components of the lamina densa and subbasal lamina on the dermal side $(22,23)$. EDTA also produces epidermal separation and we have shown that $20 \mathrm{mM}$ EDTA produces a separation similar to $1 \mathrm{M} \mathrm{NaCl}$ (24). Consequently, antibody that reacts to the epidermal portion of split human skin is binding at the lamina lucida or above. All nine of our positive sera showed binding to the epidermal portion of the saline-split skin, indicating that the IgA was directed toward an antigen within or above the lamina lucida as is the case with IgG in bullous pemphigoid. This was confirmed in two patient biopsies by direct immunoelectron microscopy. Therefore, it would appear that none of our patients had the subbasal lamina type of IgA deposition described by others. LABD is an uncommon disease and we have no further explanation for the paucity of such cases in our series.

We initially evaluated high concentrations of epidermal and dermal extracts of saline-split skin for binding of LABD IgA-class antibodies. We were unable to identify any consistent pattern on epidermal extract but were able to identify a consistent band at $97 \mathrm{kD}$ in dermal extract using the four highest titer sera. Because these IgA-class antibodies were found to react with the epidermal portion of saline-split skin on indirect immunofluorescence, we would have expected the sera to react with epidermal extract rather than dermal extract. When EDTA-split skin was used as a source for epidermal extract, we were able to identify the 97-kD band within epidermal extract. The amount of antigen, however, appears to be greater in dermal extract under all conditions, for with similar concentrations of extract, the $97-\mathrm{kD}$ protein band is more intense on dermal extract and was recognized by three additional sera. It seems likely that the relatively harsh conditions of $1 \mathrm{M}$ $\mathrm{NaCl}$ separation in combination with the extraction procedure quantitatively decreased the immunoreactivity of the putative antigen on Western blot while preserving some immunoreactivity on immunofluorescence. EDTA is a protease inhibitor as well as an agent that produces basement membrane zone separation and is likely to minimize protein denaturation.

We felt it was essential to show that the band demonstrated by Western blot on dermal extract and epidermal extract was actually being produced by the IgA-class antibody, which bound to the epidermal portion of split skin on indirect immunofluorescence. For this purpose, we initially devised the basement membrane zone immunoaffinity techniques. This technique allowed binding of the anti-basement membrane antibody to epidermal portions of the basement membrane with subsequent elution. These eluates were found to have titers of IgA-class anti-basement membrane zone antibody of 1:10 or greater despite the fact that protein concentrations were $<5 \mu \mathrm{g}$ in the eluate. This indicates elimination of the vast majority of nonspecific protein and presumably leaves only antibodies to basement membrane zone proteins present in the lamina lucida or above. This series of experiments showed that the base- 
ment membrane zone immunoaffinity-purified antibody reacted only with the $97-\mathrm{kD}$ antigen extracted from both epidermis and dermis. We were unable to detect discrete binding of LABD antibody to the dermal component of split skin using indirect immunofluorescence with patient serum or various affinity-purified eluates. It is our opinion that the antigen is likely produced by fibroblasts in the dermis and secreted in a soluble form with subsequent binding to the lamina lucida. Large amounts of soluble antigen could then be extracted from dermis, but not recognized as discrete fluorescence. Extraction of the epidermis and the basement membrane would then yield only small amounts of antigen which were minimally detectable by our low titer antibody. This would explain the small amount of the LABD antigen in epidermal extract and its presence in dermal extract. In contrast, the bullous pemphigoid antibody has been regularly extracted from the epidermal portion of the split skin $(12,13)$. However this antigen has also been shown to be produced by keratinocytes which are present in the tissue being extracted. It seems possible that the relatively harsh extraction conditions could release intracellular keratinocyte proteins which might well be responsible for the majority of antigens detected by bullous pemphigoid serum on Western blot rather than antigen bound at the basement membrane.

Because we used low dilutions of serum antibody and high concentrations of extract, several bands that we believed to be nonspecific were seen on Western blot of both the epidermal and dermal extract with LABD sera. Immunoaffinity purification of antibody with epidermis allowed elimination of such background and easy identification of bands by eliminating large quantities of nonspecific protein. We then sought to confirm the specificity of the $97-\mathrm{kD}$ antigen by a second line of investigation. We used nitrocellulose blots as an affinity substrate for antibody purification and then probed epidermis and dermis with the resulting antibody. This showed that the IgAclass antibody eluted from the $97-\mathrm{kD}$ antigen reacted with basement membrane, whereas antibody eluted from other bands on the blot failed to react with basement membrane as evaluated by immunofluorescence. The efficacy of elution from nitrocellulose and the maintenance of immunoreactivity of these solutions was confirmed by Western blots and demonstrated what we interpret to be shared epitopes in some cases.

The antigen identified by our LABD sera appears to be distinct from the antigen identified by Stanley and co-workers (12) because this antigen has been described as varying in size between 220 and $240 \mathrm{kD}$ and the antigen identified by LABD sera is $97 \mathrm{kD}$. Staining of our extracts with bullous pemphigoid and epidermolysis bullosa acquisita sera showed that classical 240-kD bullous pemphigoid band on epidermal extract and 290-kD epidermolysis bullosa acquisita band on dermal extract, indicating that these antigens were preserved by our extraction procedures, but not recognized by our LABD sera. Therefore, it seems reasonable to conclude that the LABD antigen in lamina lucida-type LABD is distinct from the classical 240-kD bullous pemphigoid band, and LABD does not simply represent an IgA-class immune response to the bullous pemphigoid antigen. Labib and co-workers have described occasional bullous pemphigoid sera that recognize a $97-\mathrm{kD}$ protein (13). Whether this is the same antigen recognized by our LABD sera will require further investigation.

Interestingly, our single cicatrizing conjunctivitis without cutaneous lesions showed an additional band present in both epidermal and dermal extract which was $38 \mathrm{kD}$ in size. This protein was still specific after ZIA. It is impossible to tell what role this antigen might be playing in the differential expression of disease. We present these results for interest and hope that these data will be expanded by the experience of others in this rare disease.

\section{Acknowledgments}

We would like to thank Dr. Robert A. Briggaman for performing the immunoelectron microscopy, and Dr. David Woodley for providing the epidermolysis bullosa acquisita control serum.

This work was supported in part by a grant from the National Institutes of Health, AM 35378-01, grant MO1-RR-00064 from the Division of Research Resources, and by the Veterans Administration Medical Center, Salt Lake City, UT.

\section{References}

1. Chorzelski, T. P., S. Jablonska, E. H. Beutner, S. F. Bean, and N. L. Furey. 1979. Linear IgA bullous dermatosis. In Immunopathology of the Skin. E. Beutner, T. Chorzelski, and S. Bean, editors. John Wiley and Sons, Inc., New York. 315-323.

2. Katz, S. I., and W. Strober. 1978. The pathogenesis of dermatitis herpetiformis. J. Invest. Dermatol. 70:63-75.

3. Lawley, T. J., W. Strober, H. Yaoita, and S. I. Katz. 1980. Small intestinal biopsies and HLA types in dermatitis herpetiformis with granular and linear IgA skin deposits. J. Invest. Dermatol. 78:9-12.

4. Leonard, J. N., G. P. Haffenden, N. P. Ring, R. M. H. McMinn, A. Sidgwick, J. F. Mowbray, D. J. Unsworth, E. J. Holborow, W. K. Blenkinsopp, A. F. Swain, and L. Fry. 1982. Linear IgA disease in adults. Br. J. Dermatol. 107:301-316.

5. Yaoita, H., and S. I. Katz. 1976. Immunoelectronmicroscopic localization of IgA in skin of patients with dermatitis herpetiformis. $J$. Invest. Dermatol. 67:502-506.

6. Stingl, G., H. Honigsmann, K. Holubar, and K. Wolff. 1976. Ultrastructural localization of immunoglobulins in skin of patients with dermatitis herpetiformis. J. Invest. Dermatol. 67:507-512.

7. Provost, T. T., J. C. Maize, A. R. Ahmed, J. S. Strauss, and R. L. Dobson. 1979. Unusual subepidermal bullous diseases with immunologic features of bullous pemphigoid. Arch. Dermatol. 115:156-160.

8. Bhogal, B., F. Wojnaroska, R. A. Marsden, M. M. Black, and P. H. McKee. 1987. Linear IgA bullous dermatosis of adults and children: an immunoelectron microscopic study. Br. J. Dermatol. 117:289-296.

9. Woodley, D. T., R. A. Briggaman, E. J. O'Keefe, A. O. Inman, L. L. Queen, and W. R. Gammon. 1984. Identification of the skin basement-membrane autoantigen in epidermolysis bullosa acquisita. N. Engl. J. Med. 310:1007-1013.

10. Woodley, D. T., R. E. Burgeson, G. Lunstrum, L. BrucknerTuderman, M. J. Reese, and R. A. Briggaman. 1988. Epidermolysis bullosa acquisita antigen is the globular carboxyl terminus of type VII procollagen. J. Clin. Invest. 81:683-687.

11. Stanley, J. R., P. Hawley-Nelson, S. Yuspa, E. Shevach, and S. Katz. 1981. Characterization of bullous pemphigoid antigen: a unique basement membrane protein of stratified squamous epithelia. Cell. 24:897-903.

12. Stanley, J. R., D. T. Woodley, and S. I. Katz. 1984. Identification and partial characterization of pemphigoid antigen extracted from normal human skin. J. Invest. Dermatol. 82:108-111.

13. Labib, R. S., G. J. Anhalt, H. P. Patel, D. F. Mutasim, and L. A. Diaz. 1986. Molecular heterogeneity of the bullous pemphigoid antigens as detected by immunoblotting. J. Immunol. 136:1231-1235.

14. Scaletta, L. J., J. C. Occhino, D. K. MacCallum, and J. H. 
Lillie. 1978. Isolation and immunologic identification of basement membrane zone antigens from human skin. Lab. Invest. 39:1-9.

15. Laemmli, U. K. 1970. Cleavage of structural proteins during the assembly of the head bacteriophage T4. Nature (Lond.). 227:680685.

16. Towbin, H. T., T. Staehelin, and J. Gordon. 1979. Electrophoretic transfer of proteins from polyacrylamide gels to nitrocellulose sheets: procedures and some applications. Proc. Natl. Acad. Sci. USA. 76:4350-4354.

17. Meyer, L. J., L. Carioto, and J. J. Zone. 1987. Dermatitis herpetiformis: extraction of intact IgA from granular deposits in dermal papillae. J. Invest. Dermatol. 88:559-563.

18. Olmsted, J. B. 1981. Affinity purification of antibodies from diazotized paper blots of heterogeneous protein samples. J. Biol. Chem. 256:11955-11957.

19. Smith, D. E., and P. A. Fisher. 1984. Identification, developmental regulation, and response to heat shock of two antigenically related forms of a major nuclear envelope protein in Drosophilia embryos: application of an improved method for affinity purification of antibodies using polypeptides immobilized on nitrocellulose blots. $J$. Cell Biol. 99:20-28.

20. Hall, R. P. 1987. The pathogenesis of dermatitis herpetiformis: recent advances. J. Am. Acad. Dermatol. 26:1129-1144.

21. Kadunce, D. P., L. J. Meyer, and J. J. Zone. 1989. IgA class antibodies in dermatitis herpetiformis: reaction with tissue agents. $J$. Invest. Dermatol. 93:253-258.

22. Woodley, D. T., D. Sauder, M. J. Talley, M. Silver, G. Grotendorst, and E. Qwarnstrom. 1983. Localization of basement membrane components after dermal-epidermal junction separation. $J$. Invest. Dermatol. 81:149-153.

23. Gammon, W. R., R. A. Briggaman, A. O. Inman, L. L. Queen, and C. E. Wheeler. 1984. Differentiating anti-lamina lucida and antisublamina densa anti-BMZ antibodies by indirect immunofluorescence on $1.0 \mathrm{M}$ sodium chloride-separated skin. J. Invest. Dermatol. 82:139-144.

24. Baker, K. W., and J. E. J. Habowsky. 1983. EDTA separation and ATPase Langerhans cell staining in the mouse epidermis. J. Invest. Dermatol. 80:104-107. 